\title{
Atributos físicos, químicos e biológicos de Latossolo Amarelo na conversão de floresta primária para seringais na Amazônia
}

\author{
Rean Augusto Zaninetti(1), Adônis Moreira(2) e Larissa Alexandra Cardoso Moraes $^{(2)}$
}

\begin{abstract}
(1)Universidade Federal do Acre, Departamento de Agricultura, CEP 69920-900 Rio Branco, AC, Brasil. E-mail: reanaugusto@yahoo.com.br (2)Embrapa Soja, Rodovia João Carlos Strass, s/no, Acesso Orlando Amaral, Distrito Warta, Caixa Postal 231, CEP 86001-970, Londrina, PR, Brasil. E-mail: adonis.moreira@embrapa.br, larissa.moraes@embrapa.br
\end{abstract}

\begin{abstract}
Resumo - O objetivo deste trabalho foi quantificar os efeitos da substituição da floresta primária por seringal (Hevea spp.), quanto aos atributos físicos, químicos e biológicos de um Latossolo Amarelo distrófico na Amazônia Central. Amostras de solo foram coletadas na profundidade de $0,0-0,1 \mathrm{~m}$, em área de floresta primária e em seringais de 2,0 ha com idades de plantio de $6,16,18,19,20$ e 45 anos. O reflorestamento das áreas por seringais não minimiza os efeitos negativos da retirada da floresta primária, com aumento do quociente metabólico e redução nos teores de carbono orgânico, carbono da biomassa microbiana (CBM), nitrogênio da biomassa microbiana (NBM), porosidade, enzimas (arilsulfatase, $\beta$-glucosidase e $\beta$-galactosidase) e substâncias húmicas (ácidos húmicos e fúlvicos e humina) do solo. O CBM e o NBM variaram de 291,97 a $615,27 \mu \mathrm{g} \mathrm{g}^{-1}$ e de 65,76 a 98,58 $\mu \mathrm{g} \mathrm{g}^{-1}$, e mostram-se como os atributos mais sensíveis às alterações decorrentes da substituição da floresta primária por seringais.
\end{abstract}

Termos para indexação: Hevea, carbono da biomassa microbiana, enzimas do solo, nitrogênio da biomassa microbiana, qualidade do solo, substâncias húmicas.

\section{Physical, chemical, and biological attributes of a Xanthic Oxisol after forest conversion to rubber tree plantation in the Amazon}

\begin{abstract}
The objective of this work was to quantify the effects of primary forest conversion into rubber tree plantation (Hevea spp.), concerning the physical, chemical, and microbiological attributes of a Xanthic Oxisol in the Central Amazon. Soil samples were collected at the $0.0-0.1 \mathrm{~m}$ depth in areas of the primary forest and of adjacent rubber tree plantations covering an area of 2.0 ha, with plant ages of $6,16,18,19$, 20 , and 45 years. The reforestation with rubber tree plantation does not minimize the negative effects of the removal of the primary forest, with increased metabolic quotient and reduction of organic carbon, microbial biomass carbon (MBC), microbial biomass nitrogen (MBN), porosity, enzymes (arilsulfatase, $\beta$-glucosidase, and $\beta$-galactosidase), and humic substances (humic and fulvic acids, and humin) in the soil. MBC and MBN ranged from 291.97 to $615.27 \mu \mathrm{g} \mathrm{g}^{-1}$ and from 65.76 to $98.58 \mu \mathrm{g} \mathrm{g}^{-1}$, respectively, and they are the most sensitive attributes to alterations resulting from the replacement of primary forest by rubber tree plantations.
\end{abstract}

Index terms: Hevea, microbial biomass carbon, soil enzymes, microbial biomass nitrogen, soil quality, humic substances.

\section{Introdução}

Florestas da Amazônia Central, estabelecidas na maior parte em solos de baixa fertilidade natural (Moreira \& Fageria, 2009), têm sua manutenção diretamente associada ao equilíbrio existente entre a cobertura vegetal, condições climáticas e os processos biogeoquímicos do solo, cuja estabilidade se deve quase exclusivamente à ciclagem de nutrientes na camada superficial do solo (Luizão, 2007; Lisboa et al., 2012).

O grau de impacto da retirada da floresta nativa para o plantio de outra cultura está relacionado ao manejo do sistema produtivo e das práticas agrícolas (Silva et al.,
2007). Nesse processo, a quantificação de alterações nos atributos químicos e biológicos do solo é um fator de destaque que tem sido utilizado para monitorar a qualidade dos solos. A atividade microbiana do solo é a principal responsável pela decomposição dos compostos orgânicos, pela ciclagem de nutrientes e pelo fluxo de energia do solo (Luizão, 2007). Portanto, a atividade da biomassa microbiana e das enzimas que atuam neste processo tem sido apontada como a característica mais sensível às alterações na qualidade do solo, causadas por mudanças de uso da terra e práticas de manejo (Cardoso et al., 2009). 
Durante muitas décadas, áreas extensivas da Amazônia têm sido desmatadas e, após poucos anos de uso, abandonadas (Cravo \& Smyth, 1997; Moreira et al., 2013). Aumento populacional, exploração da madeira, conversão em pastagem, e em agricultura de subsistência são os principais vetores por esta transformação (Johnson et al., 2001). Uma das prováveis opções para minimizar esses efeitos é a exploração dessas áreas com plantas nativas que podem ser utilizadas como reposição florestal, como a seringueira, cujo cultivo foi viabilizado na região com a técnica da enxertia de copa (Moraes et al., 2013).

Estudos sobre os efeitos na dinâmica de recuperação da qualidade física, química e biológica dos solo, os quais elucidam efeitos da retirada da floresta primária e do posterior reflorestamento com plantas nativas de potencial uso econômico da região Amazônica, são escassos, e os conhecimentos gerados estão direcionados aos efeitos da introdução de pastagem (Moraes et al., 1996; Cardoso et al., 2009; Maia et al., 2009) ou culturas anuais (Beldini et al., 2015; Moline \& Coutinho, 2015).

O objetivo deste trabalho foi quantificar os efeitos e o potencial de uso da seringueira (Hevea spp.) na substituição da floresta primária, quanto a atributos físicos, químicos e biológicos de um Latossolo Amarelo distrófico na Amazônia Central.

\section{Material e Métodos}

O estudo foi realizado em um Latossolo Amarelo distrófico típico (Oxisol) caracterizado pela baixa fertilidade natural (Tabela 1), localizado no campo experimental da Embrapa Amazônia Ocidental $\left(3^{\circ} 8^{\prime} 25^{\prime \prime} \mathrm{LS}\right.$ e $\left.59^{\circ} 52^{\prime} \mathrm{LW}\right)$. O clima dominante é o tropical úmido, do tipo Afi pela classificação de Köppen, apresentando chuvas relativamente abundantes durante todo o ano (média de $2.250 \mathrm{~mm}$ ), sendo que a quantidade de chuva no mês de menor precipitação é sempre superior a $60 \mathrm{~mm}$. A temperatura média é de aproximadamente $26^{\circ} \mathrm{C}$ (Antonio, 2010).

A cronossequência foi formada por uma floresta primária de referência e seringais de aproximadamente dois hectares (476 plantas ha-1 ${ }^{-1}$, espaçamento de 8,0x2,5 $\mathrm{m}$ ), adjacentes, com copas de Hevea pauciflora (Spruce ex Benth.) Müell Arg. e híbridos de H. pauciflora $\times$ $H$. guianensis Aubl. tolerantes ao M. ulei, agente causal do mal-das-folhas (Moraes et al., 2013) com idades de 6, 16, 18, 19, 20 e 45 anos após plantio. Para o estabelecimento dos seringais foi removida a mata nativa com a retirada das árvores de interesse econômico e posterior enleiramento e queima do restante do material vegetal. Exceto no seringal com 45 anos, a adubação de plantio foi feita de acordo com as recomendações indicadas por Pereira \& Pereira (1986).

As coletas de solo foram realizadas de acordo com a metodologia descrita por Moraes et al. (1996). Cinco amostras de cada área foram retiradas com trado do tipo caneco, na profundidade de $0,0-0,1 \mathrm{~m}$; a primeira no centro da área, e as demais a cada 25 metros, orientadas na direção dos pontos cardeais. Posteriormente, essas amostras foram divididas em duplicadas e acondicionadas em sacos de plástico e conservadas em geladeira numa temperatura média de $8^{\circ} \mathrm{C}$ para a realização das análises microbiológicas.

$\mathrm{Na}$ estimativa da quantificação do carbono da biomassa microbiana (CBM) e nitrogênio da biomassa microbiana (NBM), foi utilizado o método de irradiação e extração (IE), descrito por Ferreira et al. (1999). O CBM também foi determinado indiretamente (Anderson \& Domsch, 1978), utilizando o IRGA (Infra Red Gas Analyzer). Neste método, a respiração induzida com glicose foi transformada em biomassa microbiana com a fórmula: $\mathrm{CBM}$ em $\mu \mathrm{g} \mathrm{g}^{-1}$ solo $=\left(\right.$ respiração em $\left.\mu \mathrm{LCO}_{2} \min ^{-1} \mathrm{~g}^{-1} \times 40,04\right)+0,37$. Para estimativa do CBM e NBM, foram utilizados os fatores de correção $\left(\mathrm{K}_{\mathrm{EC}}\right.$ e $\left.\mathrm{K}_{\mathrm{EN}}\right)$ iguais a 0,45 e 0,54 , respectivamente (Balota et al., 1998).

A respiração basal $\left(\mu \mathrm{g}^{-1}\right.$ dia $^{-1}$ solo $\left.\mathrm{C}-\mathrm{CO}_{2}\right)$ foi obtida na terceira leitura sequencial do IRGA, antes da adição de $0,24 \mathrm{~g}$ de glicose e 0,50 $\mathrm{g}$ de talco inerte (Anderson \& Domsch, 1978). O fluxo de $\mathrm{CO}_{2}\left(\mathrm{~mL} \mathrm{~min}^{-1}\right)$ foi definido pela média da oitava, nona e décima leituras do IRGA. A glicose foi adicionada às amostras de solo após a sexta leitura definida pela fórmula $\mathrm{N}=\mathrm{N}_{0} \mathrm{e}^{\mathrm{kt}}$, em que $\mathrm{N}$ é a concentração inicial de microrganismos, $\mathrm{k}$ é a taxa de crescimento específico, e t é o tempo de estabilização da respiração basal (Steiner et al., 2007).

$\mathrm{O}$ quociente metabólico $\left(q \mathrm{CO}_{2}\right)$, que representa a quantidade de $\mathrm{CO}_{2}$ liberada por unidade de biomassa microbiana, foi obtido dividindo-se a respiração basal pelo teor de CMB do solo (Steiner et al., 2007). Para extração e fracionamento químico da matéria orgânica [C solúvel em água - CSA, matérias húmicas (ácidos fúlvicos - CAF, ácidos húmicos - $\mathrm{CAH}$ ) e humina - CHU], foram utilizados os métodos descritos por 
Schnitzer (1982). As atividades das enzimas do solo, associadas ao ciclo do $\mathrm{C}(\beta$-glucosidase, $\beta$-galactosidase e arilsulfatase) foram estimadas de acordo com Tabatabai (1994), utilizando-se o $\rho$-nitrofenol como indicador.

Após a realização das análises microbiológicas, o restante do solo (300 g) foi secado ao ar, peneirado e levado ao laboratório para determinação dos atributos químicos. Utilizando-se as metodologias descritas em Claessen (1997), foram determinados o pH em água na relação terra-solução 1:2,5 (m:v); o cálcio $\left(\mathrm{Ca}^{2+}\right)$, magnésio $\left(\mathrm{Mg}^{2+}\right)$, alumínio trocável $\left(\mathrm{Al}^{3+}\right)$ extraídos com a solução de $\mathrm{KCl} 1,0 \mathrm{~mol} \mathrm{~L}^{-1}$; os teores de $\mathrm{K}$ e P disponível extraídos com $\mathrm{H}_{2} \mathrm{SO}_{4} 0,025 \mathrm{~mol} \mathrm{~L}^{-1}+\mathrm{HCl}$ $0,05 \mathrm{~mol} \mathrm{~L}^{-1}$ (extrator Mehlich-1), acidez potencial $\left(\mathrm{H}^{+}+\mathrm{Al}^{3+}\right)$ com a solução tampão SMP (Moreira et al., 2004) e o carbono orgânico (Corg) pelo método de Walkley-Black $(\mathrm{MOS}=\mathrm{C} \times 1,724)$.

Na determinação dos atributos físicos do solo [textura, densidade do solo (Ds), densidade da partícula (Dp) e porosidade], foram retiradas três amostras indeformadas de cada sistema na profundidade de $0-0,10 \mathrm{~m}$, a 0,30 $\mathrm{m}$ de distância de três pontos escolhidos ao acaso da amostra retirada para determinação dos atributos químicos e biológicos do solo. As determinações da textura (areia, silte e argila), Ds e Dp foram feitas de acordo com os métodos descritos por Claessen et al. (1997). A porosidade do solo (\%) foi calculada pela fórmula [(Dp-Ds)/Dp] $\times 100$.

Tabela 1. Caracterização física do Latossolo Amarelo distrófico, na camada de $0-0,10 \mathrm{~m}$ de profundidade, sob floresta primária e seringais com diferentes idades ${ }^{(1)}$.

\begin{tabular}{ccccccc}
\hline Sistemas & Areia & Silte & Argila & Ds & Dp & $\begin{array}{c}\text { Porosidade } \\
\left(\mathrm{g} \mathrm{kg}^{-1}\right)--------\end{array}$ \\
\hline Floresta & $185,6 \mathrm{a}$ & $171,0 \mathrm{a}$ & $643,4 \mathrm{a}$ & $0,80 \mathrm{c}$ & $2,48 \mathrm{a}$ & $67,7 \mathrm{a}$ \\
Seringais & & & & & & \\
45 anos & $187,0 \mathrm{a}$ & $166,3 \mathrm{a}$ & $646,7 \mathrm{a}$ & $0,84 \mathrm{~b}$ & $2,52 \mathrm{a}$ & $66,7 \mathrm{~b}$ \\
20 anos & $183,4 \mathrm{a}$ & $184,6 \mathrm{a}$ & $632,0 \mathrm{a}$ & $0,85 \mathrm{~b}$ & $2,46 \mathrm{a}$ & $65,4 \mathrm{~b}$ \\
19 anos & $180,8 \mathrm{a}$ & $140,1 \mathrm{a}$ & $679,1 \mathrm{a}$ & $0,85 \mathrm{~b}$ & $2,49 \mathrm{a}$ & $65,9 \mathrm{~b}$ \\
18 anos & $188,9 \mathrm{a}$ & $173,0 \mathrm{a}$ & $638,1 \mathrm{a}$ & $0,92 \mathrm{~b}$ & $2,50 \mathrm{a}$ & $63,2 \mathrm{~b}$ \\
16 anos & $205,5 \mathrm{a}$ & $155,6 \mathrm{a}$ & $638,9 \mathrm{a}$ & $0,95 \mathrm{~b}$ & $2,52 \mathrm{a}$ & $61,5 \mathrm{~b}$ \\
6 anos & $176,0 \mathrm{a}$ & $180,7 \mathrm{a}$ & $643,3 \mathrm{a}$ & $1,04 \mathrm{a}$ & $2,50 \mathrm{a}$ & $58,4 \mathrm{c}$ \\
\hline Média & 187,7 & 167,3 & 645,9 & 0,89 & 2,50 & 65,1 \\
\hline CV $(\%)$ & 12,41 & 14,55 & 11,44 & 7,57 & 6,12 & 8,54 \\
\hline
\end{tabular}

${ }^{(1)}$ Médias seguidas por letras iguais, não diferem pelo teste de Scott Knott, a $5 \%$ de probabilidade. Ds, densidade do solo; e Dp, densidade da partícula.
Os dados foram analisados como blocos casualizados com cinco repetições. Na comparação dos tratamentos foi realizada análise da variância e teste $\mathrm{F}$ para detectar efeito de local e dentro de local de amostragem e aplicado o teste de Scott-Knott a 5\% de probabilidade para comparação de médias dos sete sistemas avaliados. Foi realizada a correlação a 5\% de probbabilidade para verificar a eficiência dos métodos de determinação do CBM (IE e IRGA).

\section{Resultados e Discussão}

Os teores de areia, silte e argila no solo da floresta primária e dos seringais não apresentaram diferenças estatísticas, e variaram de 176,0 a 205,5, 140,1 a 184,6 e 632,0 a $679,1 \mathrm{~g} \mathrm{~kg}^{-1}$, respectivamente (Tabela 1). Essa mesma tendência foi observada para a densidade da partícula (Dp), que ficou na faixa de 2,46 a 2,52 $\mathrm{g} \mathrm{cm}^{-3}$. Com relação à densidade do solo (Ds), houve aumento significativo com a introdução dos seringais. Resultados semelhantes foram obtidos por Silva et al. (2009), ao verificarem que o aumento da Ds e a diminuição da porosidade em plantio de espécies florestais estão relacionados ao tempo de utilização da área, exploração pelas raízes, exposição do solo às condições climáticas até o fechamento do dossel $\mathrm{e}$ formação e qualidade da serapilheira.

Somente o pH não apresentou diferença significativa entre a floresta primária e os seringais (Tabela 2). Independentemente da significância estatística ou

Tabela 2. Atributos químicos de um Latossolo Amarelo distrófico, na camada de $0-0,10 \mathrm{~m}$ de profundidade, sob floresta primária e seringais com diferentes idades ${ }^{(1)}$.

\begin{tabular}{lcccccccc}
\hline Sistemas & $\mathrm{pH}$ & $\mathrm{P}$ & $\mathrm{K}$ & $\mathrm{Ca}^{2+}$ & $\mathrm{Mg}^{2+}$ & $\mathrm{H}^{+}+\mathrm{Al}^{3+}$ & $\mathrm{CTC}$ & $\mathrm{V}$ \\
& $\mathrm{H}_{2} \mathrm{O}$ & $--\left(\mathrm{mg} \mathrm{dm}^{-3}\right)--$ & $--------\left(\mathrm{cmol}_{\mathrm{c}}\right.$ & $\left.\mathrm{dm}^{-3}\right)-------$ & $-(\%)-$ \\
\hline Floresta & $4,13 \mathrm{a}$ & $2,07 \mathrm{~b}$ & $42,0 \mathrm{a}$ & $0,10 \mathrm{~b}$ & $0,17 \mathrm{a}$ & $9,90 \mathrm{a}$ & $10,28 \mathrm{a}$ & $3,70 \mathrm{a}$ \\
Seringais & & & & & & & & \\
45 anos & $4,38 \mathrm{a}$ & $1,20 \mathrm{~b}$ & $20,8 \mathrm{c}$ & $0,07 \mathrm{c}$ & $0,08 \mathrm{c}$ & $7,77 \mathrm{a}$ & $7,97 \mathrm{~b}$ & $2,51 \mathrm{~b}$ \\
20 anos & $4,05 \mathrm{a}$ & $3,50 \mathrm{a}$ & $22,8 \mathrm{c}$ & $0,02 \mathrm{c}$ & $0,07 \mathrm{c}$ & $9,36 \mathrm{a}$ & $9,55 \mathrm{a}$ & $1,99 \mathrm{~b}$ \\
19 anos & $3,79 \mathrm{a}$ & $3,51 \mathrm{a}$ & $30,4 \mathrm{~b}$ & $0,17 \mathrm{a}$ & $0,11 \mathrm{~b}$ & $8,81 \mathrm{a}$ & $9,17 \mathrm{a}$ & $3,93 \mathrm{a}$ \\
18 anos & $4,14 \mathrm{a}$ & $1,09 \mathrm{~b}$ & $22,2 \mathrm{c}$ & $0,04 \mathrm{c}$ & $0,04 \mathrm{c}$ & $4,92 \mathrm{~b}$ & $5,06 \mathrm{c}$ & $2,77 \mathrm{~b}$ \\
16 anos & $4,16 \mathrm{a}$ & $4,13 \mathrm{a}$ & $35,2 \mathrm{~b}$ & $0,12 \mathrm{~b}$ & $0,13 \mathrm{~b}$ & $7,71 \mathrm{a}$ & $8,05 \mathrm{~b}$ & $4,22 \mathrm{a}$ \\
6 anos & $3,97 \mathrm{a}$ & $1,78 \mathrm{~b}$ & $20,0 \mathrm{c}$ & $0,06 \mathrm{c}$ & $0,06 \mathrm{c}$ & $6,49 \mathrm{~b}$ & $6,66 \mathrm{c}$ & $2,55 \mathrm{~b}$ \\
\hline Média & 4,09 & 2,47 & 17,6 & 0,08 & 0,09 & 7,85 & 8,11 & 3,10 \\
\hline CV (\%) & 8,17 & 12,14 & 15,41 & 9,63 & 8,55 & 7,97 & 10,04 & 9,96 \\
\hline (1)Médias seguidas por letras iguais, não diferem pelo teste de Scott Knott, \\
a 5\% de probabilidade.
\end{tabular}

Pesq. agropec. bras., Brasília, v.51, n.9, p.1061-1068, set. 2016 DOI: $10.1590 / \mathrm{S} 0100-204 X 2016000900005$ 
não, os valores do $\mathrm{P}$ e $\mathrm{K}$ disponível, $\mathrm{Ca}^{2+}$ e $\mathrm{Mg}^{2+}$ trocável, acidez potencial $\left(\mathrm{H}^{+}+\mathrm{Al}^{3+}\right)$ e saturação por bases (V) obtidos nos seringais não são relevantes em termos de fertilidade do solo, visto que mesmo com as modificações verificadas com a introdução desta cultura, esses valores permaneceram dentro das faixas indicadas por Alvarez V. et al. (1999) como baixa e muito baixa. No caso da CTC, corroborando Moreira \& Fageria (2009), em levantamento da fertilidade do solo do Estado do Amazonas, os altos teores de $\mathrm{H}^{+}+\mathrm{Al}^{3+}$ trocável são os que predominam no complexo de troca de cátions (CTC) do solo da região. Como os seringais foram adubados somente no plantio, as pequenas diferenças nos teores dos nutrientes no solo podem ser atribuídas a um provável efeito residual, à variação do material vegetal na matéria orgânica do solo (MO) e da decomposição da serapilheira no local amostrado (Silva et al., 2009).

No plantio dos seringais, não se confirmou o potencial esperado como planta nativa da região em elevar o teor de $\mathrm{C}$ no solo aos níveis próximos da floresta primária. Nessas áreas, a diferença foi de $68,2 \%$ no teor de C orgânico entre o seringal de seis anos de plantio e a floresta primária, enquanto na comparação com o seringal de 45 anos, a redução foi de 52,9\% (Tabela 3 ). Trabalhos realizados com plantas perenes nas mesmas condições de clima e solo apresentaram resultados semelhantes, como verificado em plantio comercial

Tabela 3. Substâncias húmicas de um Latossolo Amarelo distrófico, na camada de $0-0,10 \mathrm{~m}$ de profundidade, sob floresta primária e seringais com diferentes idades ${ }^{(1)}$.

\begin{tabular}{|c|c|c|c|c|c|c|}
\hline \multirow[t]{3}{*}{ Sistemas } & \multirow{3}{*}{$\begin{array}{l}\text { C solúvel } \\
\text { em água }\end{array}$} & \multicolumn{2}{|c|}{ Humina } & \multicolumn{2}{|c|}{ Ácidos } & \multirow{3}{*}{$\begin{array}{l}\text { Matéria } \\
\text { húmica }\end{array}$} \\
\hline & & $\mathrm{C}$ & $\mathrm{N}$ & Fúlvicos & Húmicos & \\
\hline & & --------- & -----(g & $\left.\mathrm{kg}^{-1}\right)---$ & & \\
\hline Floresta & $0,84 \mathrm{a}$ & $36,39 a$ & $3,56 \mathrm{a}$ & $4,27 \mathrm{a}$ & $1,32 \mathrm{a}$ & $4,94 a$ \\
\hline \multicolumn{7}{|l|}{ Seringais } \\
\hline 45 anos & $0,73 \mathrm{a}$ & $18,30 \mathrm{~b}$ & $1,86 \mathrm{~b}$ & $3,03 \mathrm{~b}$ & $0,84 b$ & $2,66 b$ \\
\hline 20 anos & $0,69 \mathrm{a}$ & $16,99 \mathrm{~b}$ & $2,36 \mathrm{~b}$ & $3,30 \mathrm{~b}$ & $1,07 \mathrm{~b}$ & $3,66 \mathrm{~b}$ \\
\hline 19 anos & $0,67 \mathrm{a}$ & $21,77 b$ & $1,33 b$ & $3,07 b$ & $1,21 \mathrm{a}$ & $2,04 b$ \\
\hline 18 anos & $0,79 a$ & $23,73 b$ & $1,37 \mathrm{~b}$ & $2,31 b$ & $0,99 \mathrm{~b}$ & $3,11 \mathrm{~b}$ \\
\hline 16 anos & $0,80 \mathrm{a}$ & $25,48 b$ & $2,59 b$ & $3,43 b$ & $1,10 \mathrm{~b}$ & $2,87 \mathrm{~b}$ \\
\hline 6 anos & $0,82 \mathrm{a}$ & $10,44 \mathrm{c}$ & $1,71 \mathrm{~b}$ & $2,98 \mathrm{~b}$ & $0,92 \mathrm{~b}$ & $3,47 \mathrm{~b}$ \\
\hline Média & 0,76 & 19,44 & 2,11 & 3,20 & 1,06 & 3,25 \\
\hline CV (\%) & 12,74 & 15,63 & 14,85 & 16,59 & 12,13 & 14,48 \\
\hline
\end{tabular}

Pesq. agropec. bras., Brasília, v.51, n.9, p.1061-1068, set. 2016 DOI: 10.1590/S0100-204X2016000900005 de citros de cinco anos de idade (20,7\%), mesmo com a presença de gramíneas nas entrelinhas, conforme também reportado por Moreira et al. (2011). Além da alteração da ciclagem de nutrientes após retirada da floresta primária, Luizão (2007) e Silva et al. (2009) relatam que tais resultados também estão associados à rápida mineralização da $\mathrm{MOS}$, o que acarreta menor produção de serapilheira na camada superficial do solo (Moreira et al., 2013).

O CBM e o NBM revelaram variações significativas entre a floresta primária e os seringais e não se correlacionaram com o teor de $\mathrm{C}$ no solo. Os valores de CBM variaram de 267,75 a $615,27 \mathrm{mg} \mathrm{g}^{-1}$ (IE) e 102,43 a $265,25 \mathrm{mg} \mathrm{g}^{-1}$ (IRGA), enquanto os de NBM foram de 56,67 a $98,58 \mathrm{mg} \mathrm{g}^{-1}$, sendo os maiores valores verificados na área com floresta primária (Tabela 4). Entre os seringais, o plantio com 45 anos apresentou os maiores valores, no entanto não foram detectadas diferenças significativas do teor de C orgânico entre os seringais de 45 a 18 anos, o que demonstra, conforme verificado por Chaer \& Tótola (2007), que o CBM e o $\mathrm{NBM}$ são mais sensíveis que o teor de $\mathrm{C}$ às alterações decorrentes do uso do solo.

A respiração basal, relação $\mathrm{CBM} / \mathrm{Corg} \mathrm{e} \mathrm{N}$ total não apresentaram tendência em razão do tempo e do tipo de cobertura vegetal (Tabela 4), e demonstra não serem variáveis adequadas para quantificar as alterações no estoque de $\mathrm{C}$ na recuperação de áreas desmatadas. $\mathrm{O}$ quociente metabólico $\left(q \mathrm{CO}_{2}\right)$ apresentou menor valor no solo sob floresta primária e relação inversa com o CBM obtido indiretamente com o IRGA $\left(\mathrm{CBM}=31,341-0,0303 \times q \mathrm{CO}_{2}, \mathrm{r}=0,58, \mathrm{p} \leq 0,05\right)$, cujo maior valor foi no plantio de 6 anos de idade (14,44 $\mathrm{mg} \mathrm{g}^{-1} \mathrm{~h}^{-1} \mathrm{CO}_{2}$ ). Segundo Anderson \& Domsch (1993), valores mais elevados de $q \mathrm{CO}_{2}$ estão associados a ecossistemas menos estáveis, ou seja, a elevação e estabilização dos teores de $\mathrm{C}$ orgânico causam diminuição na atividade metabólica e aumento do CBM do solo. De acordo com Silva et al. (2007), valores elevados de $q \mathrm{CO}_{2}$ são indicativos de ecossistemas submetidos a alguma condição de estresse ou distúrbio do solo. O fluxo de $\mathrm{CO}_{2}$ não foi influenciado pela cobertura vegetal, enquanto a maior relação $\mathrm{C} / \mathrm{N}$ $(12,96)$ verificada na floresta primária (Tabela 4) se deve a fatores como galhos, folhas e frutos com diferentes quantidades de lignina decorrentes da diversidade de espécies neste ecossistema. A maior quantidade de NBM na floresta primária indica maior 
capacidade de imobilização de $\mathrm{N}$ desse ecossistema, com redução das perdas do nutriente por lixiviação (Vargas \& Scholles, 1998).

Corroborando Moreira \& Malavolta (2004) e Moreira et al. (2011), o CBM determinado pelos métodos irradiação e extração (IE) e IRGA apresentou correlação significativa $(\hat{\mathrm{y}}=141,920+1,759 \mathrm{x}, \mathrm{r}=0,82$, $\mathrm{p} \leq 0,05)$ e demonstrou ser adequado na determinação do CBM nas condições edafoclimáticas estudadas. Porém, na correlação dos dois métodos, a estimativa de $\mathrm{C}-\mathrm{CO}_{2}$ microbiano feita indiretamente com o IRGA revelou valores, na média, 2,28 vezes menores que o IE (Tabela 4).

O maior valor de atividade enzimática da $\beta$-galactosidade ocorreu na floresta primária $(56,4$ $\mathrm{mg} \mathrm{g}^{-1} \mathrm{~h}^{-1}$ ), e da arilsulfatase e $\beta$-glucosidade, na floresta primária $\left(43,1 \mathrm{e} 55,6 \mathrm{mg} \mathrm{g}^{-1} \mathrm{~h}^{-1}\right)$ e no seringal de 45 anos (41,55 e 56,7 $\left.\mathrm{mg} \mathrm{g}^{-1} \mathrm{~h}^{-1}\right)$, diferindo estatisticamente dos seringais com 6, 16, 18, 19 e 20 anos de implantação (Figura 1). As alterações nessas enzimas nas diferentes coberturas vegetais podem ser explicadas pelo fato de elas atuarem na degradação de carboidratos do solo; a $\beta$-glucosidase atua na hidrólise de maltose e celubiose e a $\beta$-galactosidase pela hidrólise de melibiose e lactose, os quais são importantes fontes de energia metabólica para microbiota do solo (Eivazi \& Tabatabai, 1988; Boyle et al., 2005). A arilsulfatase, por estar presente em fungos na forma de ésteres sulfatos, também participa como componente da formação da biomassa microbiana do solo (Bandick \& Dick, 1999).

As frações da MO apresentaram predomínio da fração humina, seguida pelas frações ácidos húmicos e ácidos fúlvicos (Tabela 3). Os elevados valores da fração humina na floresta primária podem estar relacionados ao tamanho das moléculas e ao maior grau de estabilidade desta fração, enquanto os ácidos húmicos e fúlvicos, por apresentarem menor estabilidade, podem ter sido polimerizados ou mineralizados, o que diminuiria seu teor residual no solo (Fontana et al., 2006). O baixo teor de $\mathrm{C}$ solúvel em água no seringal com cinco anos de replantio reflete a dificuldade no ataque inicial por parte das enzimas produzidas pelos microrganismos. Essas enzimas são responsáveis pelo estádio inicial de degradação dos resíduos orgânicos incorporados ao solo (Souza \& Melo, 2003).

O solo da floresta primária é constituído por maior quantidade de ácidos fúlvicos, C-humina e N-humina que os solos sob seringal (Tabela 3). Esse incremento é indicativo da melhor eficiência na humificação ocasionada pelo aumento da atividade microbiana, responsável pela síntese de substâncias mais condensadas (Rangel \& Silva, 2007). Semelhantemente ao observado com C orgânico e CBM (Tabela 4) nos solos sob seringal, as substâncias húmicas também apresentaram variação entre as idades de plantio (Tabela 3).

Tabela 4. Atributos biológicos de um Latossolo Amarelo distrófico, na camada de 0-0,10 m de profundidade, sob floresta primária e seringais com diferentes idades $^{(1)}$.

\begin{tabular}{|c|c|c|c|c|c|c|c|c|c|c|}
\hline \multirow[t]{2}{*}{ Sistema } & \multirow{2}{*}{$\begin{array}{c}\text { Corg } \\
\left(\mathrm{g} \mathrm{kg}^{-1}\right)\end{array}$} & \multicolumn{2}{|c|}{$\mathrm{CBM}\left(\mu \mathrm{g} \mathrm{C} \mathrm{g}^{-1}\right)$} & \multirow{2}{*}{$\begin{array}{c}\mathrm{RB}\left(\mathrm{g} \mathrm{g}^{-1} \mathrm{dia}^{-1}\right. \\
\left.\mathrm{C}-\mathrm{CO}_{2} \text { solo }\right)\end{array}$} & \multirow{2}{*}{$\begin{array}{c}\mathrm{QM}\left(\mu \mathrm{g}^{-1} \mathrm{~g}^{-1}\right. \\
\left.\mathrm{h}^{-1} \mathrm{CO}_{2}\right)\end{array}$} & \multirow{2}{*}{$\begin{array}{c}\text { CBM/ } \\
\text { Corg }\end{array}$} & \multirow{2}{*}{$\begin{array}{l}\text { Fluxo de } \mathrm{CO}_{2} \\
\left(\mathrm{~mL} \min ^{-1}\right)\end{array}$} & \multirow{2}{*}{$\begin{array}{c}\mathrm{NBM} \\
\left(\mu \mathrm{g} \mathrm{g}^{-1}\right)\end{array}$} & \multirow{2}{*}{$\begin{array}{l}\mathrm{N} \text { total } \\
\left(\mathrm{g} \mathrm{kg}^{-1}\right)\end{array}$} & \multirow{2}{*}{$\begin{array}{c}\text { Corg/ } \\
\mathrm{N} \text { total }\end{array}$} \\
\hline & & IE & IRGA & & & & & & & \\
\hline Floresta primária & $41,33 \mathrm{a}$ & $615,27 \mathrm{a}$ & $265,25 \mathrm{a}$ & $1,39 b$ & $5,22 \mathrm{~b}$ & $14,89 \mathrm{~b}$ & $420,46 a$ & $98,58 \mathrm{a}$ & $3,19 \mathrm{a}$ & $12,96 \mathrm{a}$ \\
\hline \multicolumn{11}{|l|}{ Seringal } \\
\hline 45 anos & $19,46 b$ & $470,42 b$ & $189,81 b$ & $1,33 \mathrm{a}$ & $7,09 b$ & $24,17 \mathrm{a}$ & $478,50 \mathrm{a}$ & $88,45 b$ & $1,77 \mathrm{~b}$ & 10,99 \\
\hline 20 anos & $26,66 \mathrm{~b}$ & $267,75 \mathrm{c}$ & $178,22 b$ & $0,83 \mathrm{a}$ & $3,87 \mathrm{c}$ & $10,04 \mathrm{~b}$ & $434,02 \mathrm{a}$ & $74,61 \mathrm{~b}$ & $3,47 \mathrm{a}$ & 7,68 \\
\hline 19 anos & $23,52 b$ & $336,18 \mathrm{c}$ & $155,58 \mathrm{~b}$ & $0,94 b$ & $6,02 b$ & $14,29 \mathrm{~b}$ & $431,46 a$ & $85,63 b$ & $2,26 b$ & 10,40 \\
\hline 18 anos & $26,84 b$ & $353,96 c$ & $102,43 \mathrm{c}$ & $1,84 \mathrm{a}$ & $3,43 \mathrm{c}$ & $13,19 b$ & $440,73 a$ & $72,68 b$ & $2,58 \mathrm{~b}$ & 10,40 \\
\hline 16 anos & $13,91 \mathrm{c}$ & $342,64 \mathrm{c}$ & $145,61 b$ & $0,56 \mathrm{~b}$ & $3,87 \mathrm{c}$ & $24,63 a$ & $454,31 \mathrm{a}$ & $56,67 \mathrm{c}$ & $1,79 b$ & 7,37 \\
\hline 6 anos & $13,13 \mathrm{c}$ & $291,97 \mathrm{c}$ & $136,76 \mathrm{~b}$ & $2,00 \mathrm{a}$ & $14,44 \mathrm{a}$ & $22,23 a$ & $416,05 \mathrm{a}$ & $65,76 \mathrm{c}$ & $1,73 b$ & 7,58 \\
\hline Média & 23,55 & 382,60 & 167,67 & 1,27 & 6,28 & 17,63 & 439,36 & 77,51 & 2,40 & $9,63 b$ \\
\hline $\mathrm{CV}(\%)$ & 15,12 & 17,41 & 16,47 & 12,88 & 12,63 & 15,74 & 14,32 & 14,54 & 11,19 & 14,11 \\
\hline
\end{tabular}

${ }^{(1)}$ Médias seguidas por letras iguais não diferem pelo teste de Scott Knott, a 5\% de probabilidade. Corg, carbono orgânico; CBM, carbono da biomassa microbiana; IE, irradiação e extração; IRGA, "infra red gas analyzer"; RB, respiração basal; QM, quociente metabólico; e NBM, nitrogênio da biomassa microbiana. 
A relação ácidos húmicos e fúlvicos variou de 0,27 a 0,42 e ficou abaixo de 1 . Kononova (1982) relata que essa relação é indicadora da qualidade do húmus e expressa o grau de evolução do processo de humificação da MO. Em solos tropicais, na sua maioria, a relação é inferior a 1 devido à menor intensidade do processo de humificação, ocasionado pelas restrições edáficas e baixo conteúdo de bases trocáveis, o que restringe a atividade biológica nos solos mais intemperizados e ácidos (Canellas et al., 2002). Maiores valores de C na fração humina implicam em maior expressão das propriedades da fração coloidal da MO do solo, com a maior retenção de cátions trocáveis, característica importante para o manejo dos solos tropicais (Souza \& Melo, 2003).

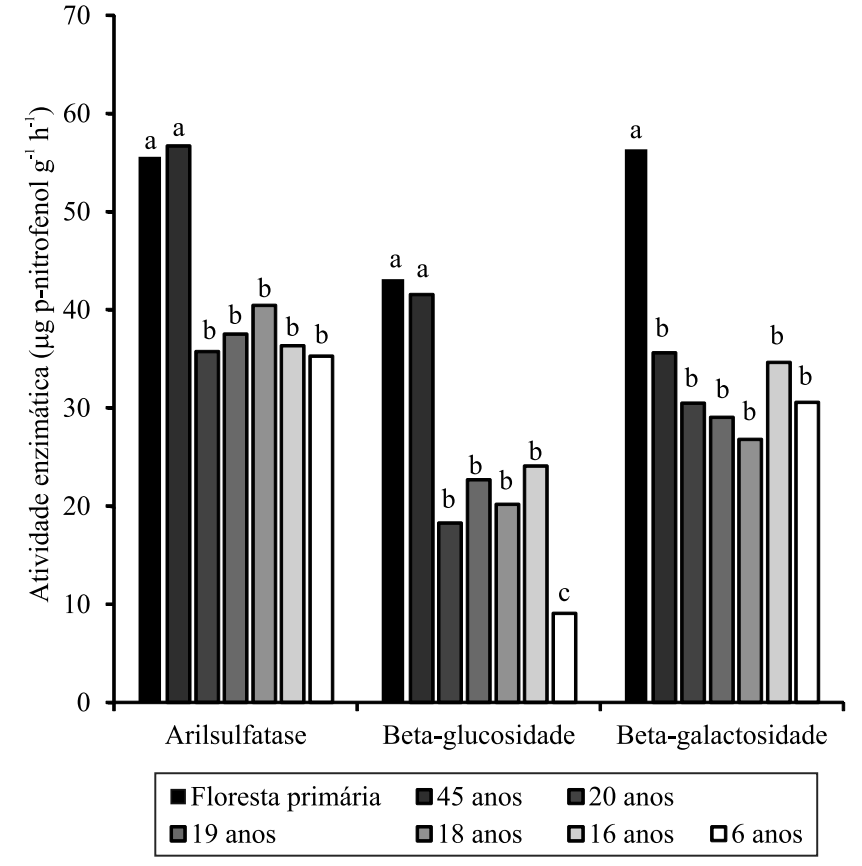

Figura 1. Atividade enzimática (arilsulfatase, $\beta$-glucosidase e $\beta$-galactosidade) de um Latossolo Amarelo distrófico, na camada de $0,0-0,1 \mathrm{~m}$ de profundidade, sob floresta primária e seringais com diferentes idades. Médias seguidas por letras iguais não diferem entre si a $5 \%$ de probabilidade, pelo teste de Scott-Knott.

\section{Conclusões}

1. A utilização de plantas nativas da região Amazônica, como a seringueira, na reposição florestal não eleva o teor de $\mathrm{C}$ no solo de volta aos níveis observados na floresta primária.

2. A retirada da floresta primária aumenta o quociente metabólico $\left(q \mathrm{CO}_{2}\right)$ e reduz os teores de $\mathrm{C}$ orgânico, CBM, NBM, porosidade, enzimas (arilsulfatase, $\beta$-glucosidase e $\beta$-galactosidase) e substâncias húmicas (ácidos húmicos e fúlvicos e humina) do solo.

3. O CBM e o NBM são os atributos mais sensíveis às alterações ocasionadas pela retirada da floresta primária na Amazônia tropical úmida.

\section{Agradecimentos}

À Universidade Federal do Amazonas (Ufam) e à Coordenação de Aperfeiçoamento de Pessoal de Nível Superior (Capes), pela bolsa de doutorado; e ao Conselho Nacional de Desenvolvimento Científico e Tecnológico (CNPq), pelo apoio financeiro e concessão de bolsa de produtividade em pesquisa.

\section{Referências}

ALVAREZ V., V.H.; NOVAIS, R.F.; BARROS, N.F.; CANTARUTTI, R.B.; LOPES, A.S. Interpretação dos resultados das análises de solos. In: RIBEIRO, A.C.; GUIMARÃES, P.T.G.; ALVAREZ V., V.H. (Ed.). Recomendação para o uso de corretivos e fertilizantes em Minas Gerais: $5^{\text {a }}$ aproximação. Viçosa: Comissão de Fertilidade do Solo do Estado de Minas Gerais, 1999. p.25-32.

ANDERSON, J.P.E.; DOMSCH, K.H. A physiological method for the quantitative measurement of microbial biomass in soils. Soil Biology and Biochemistry, v.10, p.215-221, 1978. DOI: 10.1016/0038-0717(78)90099-8.

ANDERSON, T.-H.; DOMSCH, K.H. The metabolic quotient for $\mathrm{CO}_{2}\left(q \mathrm{CO}_{2}\right)$ as a specific activity parameter to assess the effects of environmental conditions, such as $\mathrm{pH}$, on the microbial biomass of forest soils. Soil Biology and Biochemistry, v.25, p.393-395, 1993. DOI: 10.1016/0038-0717(93)90140-7.

ANTONIO, I.C. Boletim agrometeorológico 2009: Estação Agroclimatológica da Embrapa Amazônia Ocidental, no Km 29 da Rodovia AM 010. Manaus: Embrapa Amazônia Ocidental, 2010. 31p. (Embrapa Amazônia Ocidental. Documentos, 83).

BALOTA, E.L.; COLOZZI-FILHO, A.; ANDRADE, D.S.; HUNGRIA, M. Biomassa microbiana e sua atividade em solos sob diferentes sistemas de preparo e sucessão de culturas. Revista Brasileira de Ciência do Solo, v.22, p.641-650, 1998. DOI: 10.1590/S0100-06831998000400009. 
BANDICK, A.K.; DICK, R.P. Field management effects on soil enzyme activities. Soil Biology and Biochemistry, v.31, p.14711479, 1999. DOI: 10.1016/S0038-0717(99)00051-6.

BELDINI, T.P.; OLIVEIRA JUNIOR, R.C. de; KELLER, M.M.; CAMARGO, P.B. de; CRILL, P.M.; SILVA, A.D. da; SANTOS, D.B. dos; OLIVEIRA, D.R. de. Physical, chemical, and biological properties of soil under soybean cultivation and at an adjacent rainforest in Amazonia. Revista Ambiente and Água, v.10, p.707719, 2015. DOI: 10.4136/ambi-agua.1696.

BOYLE, S.I.; HART, S.C.; KAYE, J.P.; WALDROP, M.P. Restoration and canopy type influence soil microflora in a ponderosa pine forest. Soil Science Society of America Journal, v.69, p.1627-1638, 2005. DOI: 10.2136/sssaj2005.0029.

CANELLAS, L.P.; VELLOSO, A.C.X.; RUMJANEK, V.M.; GURIDI, F.; OLIVARES, F.L.; SANTOS, G. de A.; BRAZ-FILHO, R. Distribution of the humified fractions and characteristics of the humic acids of an Ultisol under cultivation of Eucalyptus and sugar cane. Terra Latinoamericana, v.20, p.371-381, 2002.

CARDOSO, E.L.; SILVA, M.L.N.; MOREIRA, F.M. de S.; CURI, $\mathrm{N}$. Atributos biológicos indicadores da qualidade do solo em pastagem cultivada e nativa do Pantanal. Pesquisa Agropecuária Brasileira, v.44, p.631-637, 2009. DOI: 10.1590/S0100204X2009000600012.

CHAER, G.M.; TÓTOLA, M.R. Impacto do manejo de resíduos orgânicos durante a reforma de plantios de eucalipto sobre indicadores de qualidade do solo. Revista Brasileira de Ciência do Solo, v.31, p.1381-1396, 2007. DOI: 10.1590/S010006832007000600016.

CLAESSEN, M.E.C. (Org.). Manual de métodos de análise de solo. 2.ed. rev. e atual. Rio de Janeiro: Embrapa-CNPS, 1997. 212p.

CRAVO, M.S.; SMYTH, T.J. Manejo sustentado da fertilidade de um latossolo da Amazônia Central sob cultivos sucessivos. Revista Brasileira de Ciência do Solo, v.21, p.607-616, 1997. DOI: 10.1590/S0100-06831997000400011.

EIVAZI, F.; TABATABAI, M.A. Glucosidades and galactosidades in soils. Soil Biology and Biochemistry, v.20, p.601-606, 1988. DOI: $10.1016 / 0038-0717(88) 90141-1$.

FERREIRA, A.S.; CAMARGO, F.A.O.; VIDOR, C. Utilização de microondas na avaliação da biomassa microbiana do solo. Revista Brasileira de Ciência do Solo, v.23, p.991-996, 1999. DOI: 10.1590/S0100-06831999000400026.

FONTANA, A.; PEREIRA, M.G.; LOSS, A.; CUNHA, T.J.F.; SALTON, J.C. Atributos de fertilidade e frações húmicas de um Latossolo Vermelho no Cerrado. Pesquisa Agropecuária Brasileira, v.41, p.847-853, 2006. DOI: 10.1590/S0100204X2006000500018.

JOHNSON, C.M.; VIEIRA, I.C.G.; ZARIN, D.J.; FRIZANO, J.; JOHNSON, A.H. Carbon and nutrient storage in primary and secondary forests in eastern Amazonia. Forest Ecology and Management, v.147, p.245-252, 2001. DOI: 10.1016/S03781127(00)00466-7.

KONONOVA, M.M. Matéria orgânica del suelo: su natureza, propriedades y métodos de investigación. Barcelona: Oikos-Tau, 1982. 365p.
LISBOA, B.B.; VARGAS, L.K.; SILVEIRA, A.O. da; MARTINS, A.F.; SELBACH, P.A. Indicadores microbianos de qualidade do solo em diferentes sistemas de manejo. Revista Brasileira de Ciência do Solo, v.36, p.45-55, 2012. DOI: 10.1590/S010006832012000100004.

LUIZÃO, F.J. Ciclo de nutrientes na Amazônia: respostas as mudanças ambientais e climáticas. Ciência e Cultura, v.59, p.3136, 2007.

MAIA, S.M.F.; OGLE, S.M.; CERRI, C.E.P.; CERRI, C.C. Effect of grassland management on soil carbon sequestration in Rondônia and Mato Grosso states, Brazil. Geoderma, v.149, p.84-91, 2009. DOI: 10.1016/j.geoderma.2008.11.023.

MOLINE, E.F. da V.; COUTINHO, E.L.M. Atributos químicos de solos da Amazônia Ocidental após sucessão da mata nativa em áreas de cultivo. Revista de Ciências Agrárias, v.58, p.14-20, 2015. DOI: $10.4322 /$ rca.1683.

MORAES, J.F.L. de; VOLKOFF, B.; CERRI, C.C.; BERNOUX, M. Soil properties under Amazon forest and changes due to pasture installation in Rondônia, Brazil. Geoderma, v.70, p.63-81, 1996. DOI: 10.1016/0016-7061(95)00072-0.

MORAES, L.A.C.; MORAES, V.H. de F.; MOREIRA, A.; CORDEIRO, E.R.; OLIVEIRA, M.C.N. de. Clones de copa de seringueira resistentes ao mal-das-folhas para o cultivo na Amazônia tropical úmida. Bragantia, v.72, p.271-278, 2013. DOI: 10.1590/brag.2013.035.

MOREIRA, A.; ALMEIDA, M.P. de; COSTA, D.G.; SANTOS, L.S. Acidez potencial pelo método do $\mathrm{pH}$ SMP no Estado do Amazonas. Pesquisa Agropecuária Brasileira, v.39, p.89-92, 2004. DOI: 10.1590/S0100-204X2004000100013.

MOREIRA, A.; FAGERIA, N.K. Soil chemical attributes of Amazonas State, Brazil. Communications in Soil Science and Plant Analysis, v.40, p.2912-2925, 2009. DOI: 10.1080/00103620903175371.

MOREIRA, A.; FAGERIA, N.K.; GARCIA Y GARCIA, A. Soil fertility, mineral nitrogen, and microbial biomass in upland soils of the Central Amazon under different plant covers. Communications in Soil Science and Plant Analysis, v.42, p.694-705, 2011. DOI: 10.1080/00103624.2011.550376.

MOREIRA, A.; MALAVOLTA, E. Dinâmica da matéria orgânica e da biomassa microbiana em solo submetido a diferentes sistemas de manejo na Amazônia Ocidental. Pesquisa Agropecuária Brasileira, v.39, p.1103-1100, 2004. DOI: 10.1590/S0100204X2004001100008.

MOREIRA, A.; MORAES, L.A.C.; ZANINETTI, R.A.; CANIZELLA, B.T. Phosphorus dynamics in the conversion of a secondary forest into rubber tree plantation in the Amazon rainforest. Soil Science, v.178, p.618-625, 2013. DOI: 10.1097/ SS.0000000000000025.

PEREIRA, A.V.; PEREIRA, E.B.C. Adubação de seringais de cultivo na Amazônia (primeira aproximação). Manaus: EmbrapaCNPSD, 1986. 32p. (Embrapa-CNPSD. Circular técnica, 8).

RANGEL, O.J.P.; SILVA, C.A. Estoques de carbono e nitrogênio e frações orgânicas de Latossolo submetido a diferentes sistemas 
de uso e manejo. Revista Brasileira de Ciência do Solo, v.31, p.1609-1623, 2007. DOI: 10.1590/S0100-06832007000600037.

SCHNITZER, M. Organic matter characterization. In: PAGE, A.L. (Ed.). Methods of soil analysis. Madison: Soil Science Society of America, 1982. p.581-594.

SILVA, L.G. da; MENDES, I. de C.; REIS JUNIOR, F.B.; FERNANDES, M.F.; MELO, J.T. de; KATO, E. Atributos físicos, químicos e biológicos de um Latossolo de cerrado em plantio de espécies florestais. Pesquisa Agropecuária Brasileira, v.44, p.613-620, 2009. DOI: 10.1590/S0100-204X2009000600010.

SILVA, M.B. da; KLIEMAN, H.J.; SILVEIRA, P.M. da; LANNA, A.C. Atributos biológicos do solo sob influência da cobertura vegetal e do sistema de manejo. Pesquisa Agropecuária Brasileira, v.42, p.1755-1761, 2007. DOI: 10.1590/S0100-204X2007001200013.

SOUZA, W.J.O.; MELO, W.J. Matéria orgânica de um Latossolo submetido a diferentes sistemas de produção de milho. Revista
Brasileira de Ciência do Solo, v.27, p.1113-1122, 2003. DOI: 10.1590/S0100-06832003000600016.

STEINER, C.; ARRUDA, M.R. de; TEIXEIRA, W.G.; ZECH, W. Soil respiration curves as soil fertility indicators in perennial central Amazonian plantation treated with charcoal, and mineral or organic fertilisers. Tropical Science, v.47, p.218-230, 2007. DOI: 10.1002/ts.216.

TABATABAI, M.A. Soil enzymes. In: WEAVER, R.W.; SCOTT, A.; BOTTOMELEY, P.J. (Ed.). Methods of soil analysis: microbiological and biochemical properties. Madison: Soil Science Society of America, 1994. p.778-835.

VARGAS, L.K.; SCHOLLES, D. Nitrogênio da biomassa microbiana, em solos sob diferentes sistemas de manejo estimado por métodos de fumigação. Revista Brasileira de Ciência do Solo, v.22, p.411-417, 1998. DOI: 10.1590/S010006831998000300006 .

$\overline{\text { Recebido em } 20 \text { de julho de } 2015 \text { e aprovado em } 11 \text { de novembro de } 2015}$ 